\title{
Effect of Inhibitors and Activators of \\ Phosphofructokinase on the Oxygen Uptake in Plants under Salinity Conditions
}

\author{
Vilayat B. Abdiyev \\ Baku State University \\ Z. Khalilov, 23, Baku, Azerbaijan AZ-1148 \\ Tel: 99-450-340-1202Ｅ-mail: vilayet52@mail.ru
}

Received: December 21, 2012 Accepted: January 4, 2013

doi:10.5296/jbls.v4i2.3335 URL: http://dx.doi.org/10.5296/jbls.v4i2.3335

\begin{abstract}
The effect of inhibitors and activators of phosphofructokinase on the absorption of oxygen by the roots of wheat seedlings was studied under normal and salinity conditions. It was revealed that in the control version the absorption of $\mathrm{O}_{2}$ by seedling roots was significantly increased and the effect of acceptor ADP was appeared after introduction of $10^{-3} \mathrm{M}$ AMP and $4 \cdot 10^{-4} \mathrm{M}$ of inorganic phosphate into the system. However, under salinity conditions the acceptor effect of ADP did not occur, and the absorption of oxygen was somewhat reduced.
\end{abstract}

Keywords: Polarography, Aerobic glycol sis, Pentose phosphate pathway, Inhibitor, Activator

\section{Introduction}

In the literature there are number of experimental studies devoted to characterization of phosphofructokinase in microorganisms, yeast and animal tissues [Torres J. et al., 1997; Macdonald J. and Storey K., 2005; Flores C. et al. 2005; Saavedra E. et al. 2005; Baquan S. et al. 2005; Valleyo J., Hardin C. 2005].

However, it should be noted that information about phosphofructokinase of plants is very scarce [Omarov J.A., 2007]. Phosphofructokinase is an important key regulatory enzyme of glycolytic pathway. Phosphofructokinase catalyzes the third reaction of glycolysis, the conversion of fructo-6-phosphate to fructose-1,6 biphosphate, consuming one molecule of ATP during this process. This reaction is one of the irreversible reactions of glycolysis.

It should be noted that the overall rate of glycol sis is limited by reaction catalyzed by 
phosphofructokinase.

Despite all mentioned the effect of inhibitors and activators of phosphofructokinase on the oxygen absorption rate by the roots of wheat seedlings under salinity conditions was not studied sufficiently. This was the reason of the present study, which was aimed to determine the effects of activators, AMP, fructose-1,6 diphosphate, ADP, phosphate; and inhibitors, ATP and citrate, of phosphofructokinase on the absorption of $\mathrm{O}_{2}$ by plant roots under salinity conditions.

\section{Materials and Methods}

The object of the study were five-day old wheat seedlings (variety 'Barakatli') grown in an incubator at $25^{\circ} \mathrm{C}$ in solutions of $\mathrm{Knop}$ and $\mathrm{NaCl}$ at concentration of $50-70 \mathrm{mM}$ under aerated conditions.

The measurement of oxygen absorption rate by seedlings roots was carried out with a polarographic setting fitted with open electrode [Kasumov N.A., 1983]. The cathode was thin platinum wires of $0.5 \mathrm{~mm}$ diameter, fused into a glass capillary. Thus, the platinum electrode was carefully isolated, except the tips, which were left 1-2mm open. Platinum electrode, fused into a glass capillary, contacts with the copper wire through mercury. As an anode (non-polarizable electrode) $\mathrm{AgCl}$ electrode that contacts with $\mathrm{KCl}$ with the liquid medium with placed inside plant, was used. The curve of dependence of diffusion amperage from the power supply voltage has a plateau. For oxygen this plateau is in the range of $0.2-0.9 \mathrm{~V}$. On the electrodes the potential difference was maintained at $0.65 \mathrm{~V}$. For recording of arising amperage the galvanometer with sensitivity of 2 10-7 A/ div (M-95) was used. The working space of the cell is formed by a cylinder of $2 \mathrm{~cm}$ depth. The sensitivity of our setup was $3 \cdot 10^{-7} \mathrm{M} \mathrm{O}_{2} / \pi$. The sensitivity of the used platinum electrodes was also tested by Winkler method, which allows determining the absolute content of oxygen in water. Zero concentration of oxygen was created by filling the cell with $1 \%$ aqueous solution of sodium sulfite. The overall block diagram of the setup is presented in Figure 1.

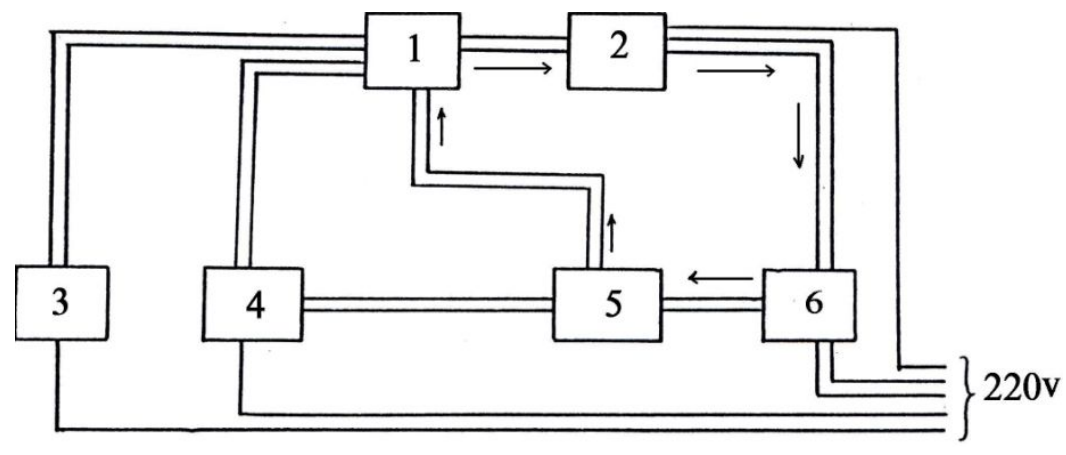

Figure 1. The overall block diagram of polarographic equipment for determination of oxygen uptake by plants. 1-electrochemical cell; 2-pH-meter; 3-reflecting galvanometer;

4-ultrathermostat; 5-thermostatic cuvette with object; 6-micropump.

As an inhibitors of phosphofructokinase the ATP at concentration $10^{-3} M$ and citrate at 
concentration $10^{-2} \mathrm{M}$ were used. The activators were: AMP at concentration $10^{-3} \mathrm{M}$, fructose-1, 6-diphosphate at concentration $10^{-3} \mathrm{M}$, ADP at concentration $10^{-4} M$ and inorganic phosphate at concentration $4 \cdot 10^{-4} M$. In addition, a classical uncoupler 2, 4-DNF at concentration $10^{-4} M$ was used. Digital materials were statistically analyzed according to G.F.Lakin [Lakin G.F., 1990]. Accuracy rate does not exceed five percent.

\section{Results and Discussion}

The substrates of phosphofructokinase are fructose-6-phosphate and ATP. Fructose-6-phosphate is binded at catalytic site of the enzyme, and ATP could be binded both at the catalytic centre and allosteric regulatory center. This could be explained by the evidence that ATP is allosteric regulator (inhibitor) of phosphofructokinase [Lee H., Copeland L., 1996; Sola-Penna M. et al. 2002; Santamaria B. et al. 2002; Susuki M. et al. 2005].

Therefore we were interested in studying the absorption of $\mathrm{O}_{2}$ by seedlings roots under the influence of the ATP. During addition of ATP, over establishment of steady-state level, the oxygen uptake by plant roots significantly decreases.

It was also found that citrate is an inhibitor of plant enzyme. In a contrast, for phosphofructokinase of animals the inhibitor is ADP. AMP, which is an activator of animals phosphofructokinase had no significant effect on the plant enzyme, but it increased the inhibition by ATP and citrate. Later the same authors [Dennis D. and Coulate T., 1987.] suggested that phosphate $\left(P_{i}\right)$ and citrate are important regulators in vivo, but they did not confirm the important regulatory role of ADP.

Organic acids play an important role in the metabolism of plants, and as substrates of high oxidation states they are involved in respiration process. The addition of $10^{-2} \mathrm{M}$ of citric acid to the system causes a significant increase in oxygen uptake by wheat seedlings. Citric acid as an organic acid increases the absorption of oxygen.

Next, we studied the $\mathrm{O} 2$ absorption by wheat seedlings under influence of ADP at concentration $10^{-4} M$. It was found that after the establishment of steady-state levels of speed, oxygen absorption by wheat roots in electrochemical cell was immediately raised after addition into the system of a small amount of $\left(10^{-4} M\right)$ ADP. After 30-40 minutes of the action of ADP $4 \cdot 10^{-4} M$ inorganic phosphate ${ }^{\left(P_{i}\right)}$ was introduced into the system. As can be seen in Figure 2 the addition of inorganic phosphate reduces the $\mathrm{O} 2$ absorption by roots of wheat seedlings. After addition of phosphate, all of the exogenous ADP converts to ATP, due to the decrease in 
the amount of phosphate acceptor. At the same time, in spite of an excess of oxidation substrate and oxygen, the rate of oxygen absorption by plant roots significantly decreases. This means that ADP is the limiting factor of the plant respiration rate.

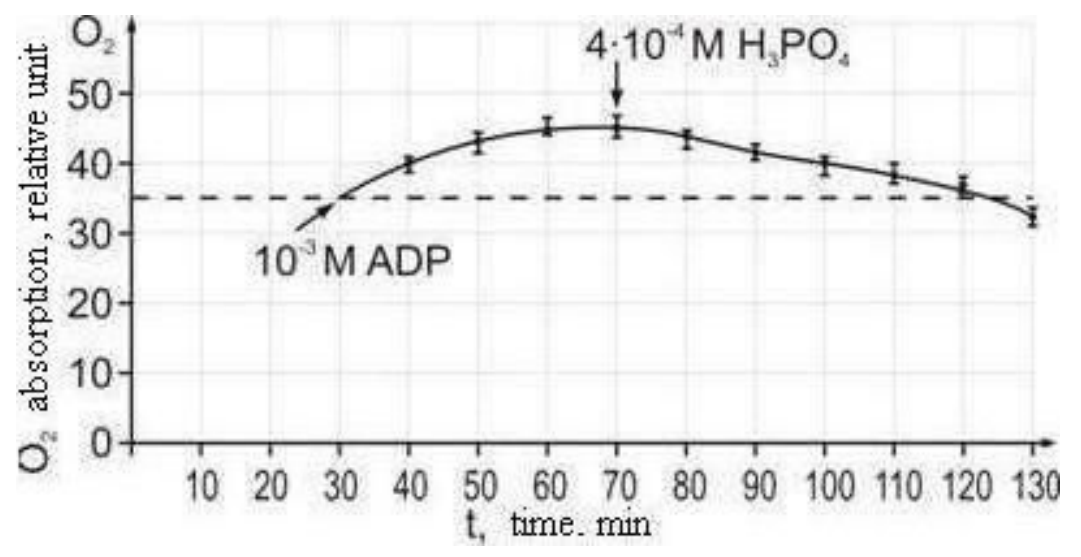

Figure 2. The kinetics curve of oxygen absorption by the roots of wheat seedlings during

$$
\text { consecutive action of ADP and } \mathrm{H}_{3} \mathrm{PO}_{4}\left(\mathrm{t}=20^{\circ} \mathrm{C}\right)
$$

It should be noted that in this case the level of ADP regulates the intensity of electron transport and oxidative phosphorylation not as an allosteric factor, but as a substrate of phosphorylation.

The experiments revealed that introduction of $10^{-3} M$ AMP into the system (after the settlement of steady-state level of oxygen absorption rate by roots of seedlings) slightly increases the absorption of oxygen, however the addition of $4 \cdot 10^{-4} M$ of inorganic phosphate $\left(P_{i}\right)$ into the system significantly increases the $\mathrm{O}_{2}$ absorption by seedlings roots and acceptor effect of ADP appears.

In the next experiments the oxygen uptake by plant roots under the action of fructose-1,6-diphosphate was studied. The experiments revealed that after introduction of $10^{-3} M$ of fructose-1,6-diphosphate into the system the oxygen uptake accelerated by approximately $40 \%$ (Figure 3 ). Increase of oxygen absorption by plant roots under the action of fructose-1, 6-diphosphate could be explained by the fact that fructose-1, 6-diphosphate is one of the major substrates of anaerobic and aerobic glycolysis and in normal conditions enhances the respiration rate of seedling. After 40-50 minutes of fructose-1, 6-diphosphate action the ADP at concentration $10^{-4} M$ was injected into the system. As we can see in the Figure 3, the addition of ADP accelerates oxygen absorption. This experiment was carried out in reverse order - first tested the action of ADP, and then the action of fructose-1, 6-diphosphate. In this case, ADP enhances the oxygen absorption, and addition of fructose-1, 6-diphosphate further enhances the oxygen absorption. 


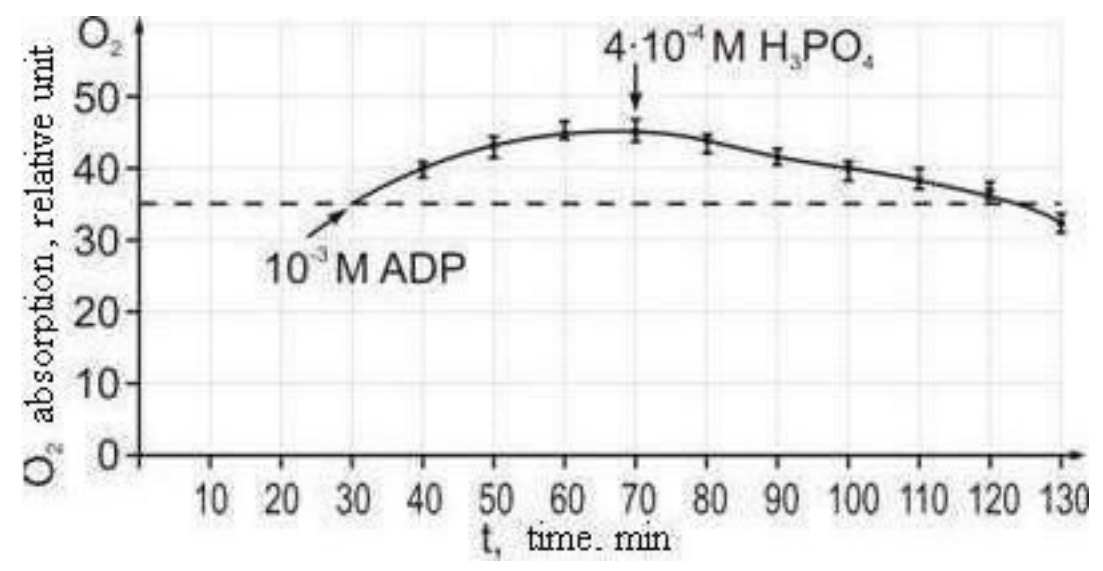

Figure 3. The kinetics curve of oxygen uptake by wheat seedlings during consecutive action of fructose-1,6-diphosphate and $\operatorname{ADP}\left(\mathrm{t}=20^{\circ} \mathrm{C}\right)$

The introduction of ATP into the system after exposure to fructose-1,6-diphosphate, does not stimulate oxygen uptake by plants, moreover it inhibited the oxygen uptake by roots of wheat seedlings and addition of fructose-1,6-diphosphate takes over its inhibitory effect and enhances the oxygen absorption by 15 per cent.

Next, we studied the combined effect of the classical uncoupler 2,4 - DNF and fructose-1,6-diphosphate in the control. Experiments revealed that addition of fructose-1,6-diphosphate into the system enhances the oxygen absorption by roots of wheat seedlings and addition of $10^{-4} \mathrm{M}$ of 2,4- DNF significantly enhances the respiration rate. These findings led us to conclusion that 2,4 - DNF has a divisive effect (Figure 4).

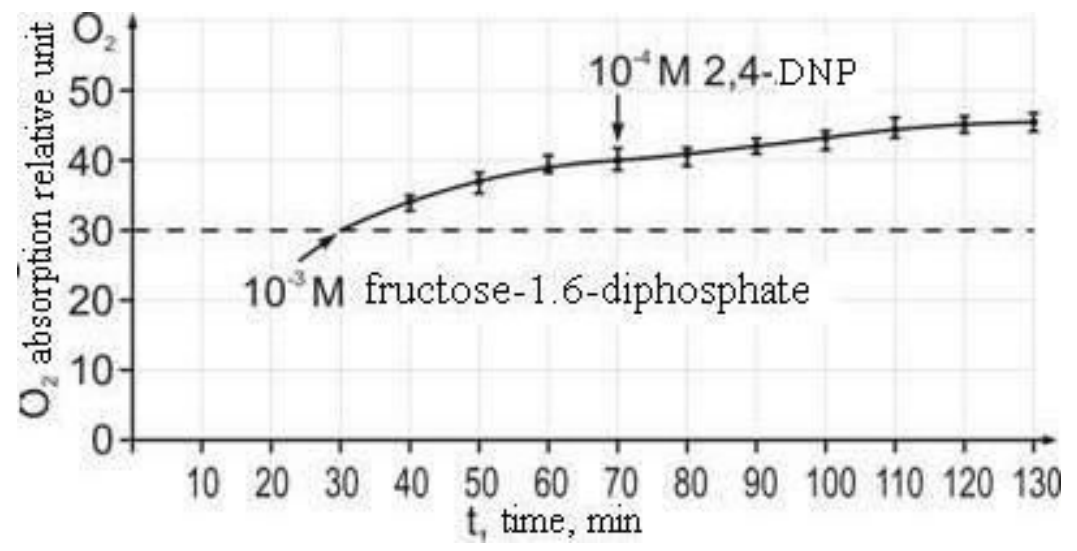

Figure 4. The kinetic curve of oxygen uptake by wheat seedlings during consecutive action of fructose-1,6-diphosphate and 2,4- DNF $\left(\mathrm{t}=20^{\circ} \mathrm{C}\right)$

In subsequent experiments, the root systems of seedlings were subjected to prolonged exposure $(50-70 \mathrm{mM} \mathrm{NaCl})$ to salt. For this purpose, seeds and roots of wheat seedlings were kept during 5-6 days in saline. After that, seedlings were transferred into the water, and after some time ATP was introduced into the system. As it can be observed in the Fig., in this case, ATP causes inhibition of $\mathrm{O}_{2}$ absorption by seedlings. The suppression of oxygen absorption rate by effect of ATP, apparently due to the fact that the seedlings were exposed long enough to salt, and 
therefore aerobic glycolisis started to increase in the tissues of the root system [Kasumov N.A., 2004]. With increase of aerobic glycolysis the synthesis of endogenous ATP enhances. In this case, the addition of exogenous ATP at the expense of feedback is the reason of the process weakening.

The introduction of fructose-1,6 diphosphate in the system after effect of ATP takes out its inhibitory effect and increases the oxygen uptake (Figure 5).

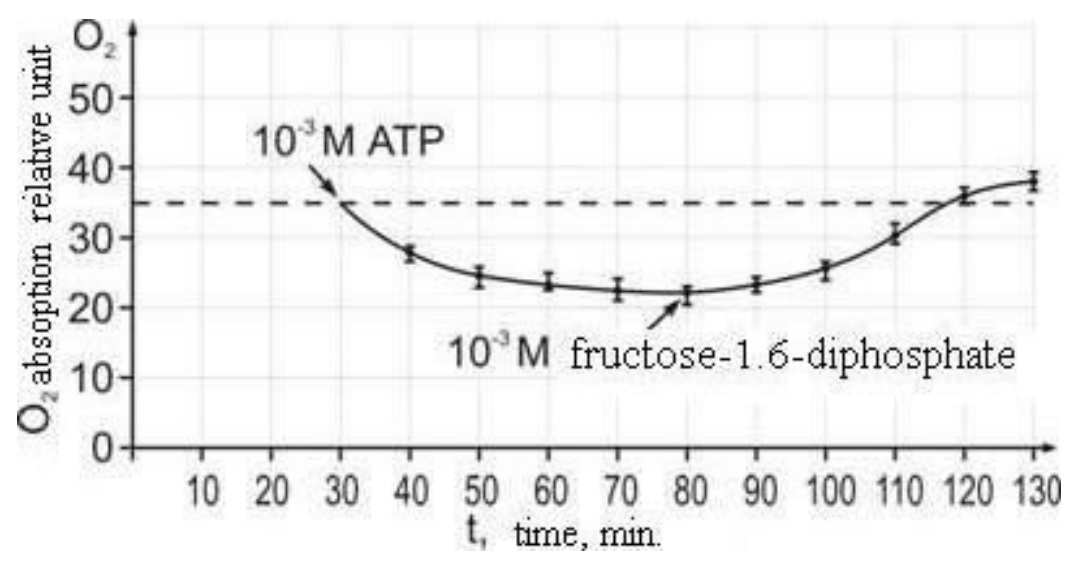

Figure 5. The kinetics of oxygen uptake by wheat seedlings during prolonged exposure to $\mathrm{NaCl}$ at concentration $70 \mathrm{mM} \quad\left(\mathrm{t}=20^{\circ} \mathrm{C}\right)$

It should be noted that in the absence of salinity the oxidative phosphorylation in young seedlings occurs intensively and therefore addition of exogenous ATP inhibits oxygen uptake by plant roots due to excess of exogenous ATP.

It was found that after the introduction of $10^{-3} M$ AMP into the system the oxygen uptake of seedlings roots remains almost unchanged. However, when $4 \cdot 10^{-4} M$ of inorganic phosphate $\left(P_{i}\right)$ added into the system, a decrease of oxygen uptake is observed.

In experiments conducted with phosphofructokinase from grapefruit juice, it was shown that ATP is an inhibitor of the enzyme at a concentration of more than $80 \mathrm{~mm}$ [Van Praag E. et al., 1999].

When ADP added into the system at a concentration of $10^{-4} \mathrm{M}$ the $\mathrm{O}_{2}$ uptake by plant roots significantly reduces and non-acceptor role appears.

Our data are in accordance with published literature [Susuki et.al., 2003]. The cells suspension from the culture of B.sexandula increased the intensity of respiration under exposure to $150 \mathrm{mM} \mathrm{NaCl}$, which was accompanied by a decrease in content of fructose-6-phosphate and increased levels of fructose-1,6-bisphosphate, as well as activation of glycolytic enzymes (GF). High concentrations of ATP inhibited the phosphofructokinase activity, but this effect was completely eliminated by $\mathrm{NaCl}$. It is supposed that increase in the activity of these enzymes 


\section{Ml Macrothink}

(GF) under influence of $\mathrm{NaCl}$ is one of the mechanisms of salt resistance in mangrove cells.

The experiments revealed that addition of citric acid into the system causes inhibition of $\mathrm{O}_{2}$ uptake by seedlings. It was determined that by exposure to citric acid the oxygen uptake by plant roots in 5-day seedlings decreased for 23\%, in 7-day seedlings for 34\%, and in 9-day seedlings for $62 \%$. Next we studied the oxygen uptake by plant roots under the effect of fructose-1,6-diphosphate. It was found that after introduction of $10^{-3} M$ of fructose-1,6-diphosphate into the system the oxygen uptake by plant roots increased (70\%). This may be due to the fact that fructose-1,6-diphosphate is one of the major substrates of aerobic glycolysis. Fructose-1,6-diphosphate is easily converted to 3-phosphoglyceric aldehyde.

It is important to highlight that at non-oxidizing stage pentose phosphate pathway is associated with glycolysis (through glucose-6-phosphate, fructose-1,6-phosphate and 3-phosphoglyceric aldehyde), thus there is a possibility to turn oxidative processes to hexose monophosphate direction [Severin E.S., 2004].

It was determined that during increase of sodium chloride concentration $(50-70 \mathrm{mM})$, increase of oxygen uptake by plant roots under the action of fructose-1,6-diphosphate enhances, that indicates the presence of additivity in their action.

The introduction of $10^{-4} M$ of 2,4-DNF into the system during long-term exposure to salts in the presence of fructose-1,6-diphosphate does not stimulate oxygen uptake by plants, moreover inhibits this process (Figure 6).

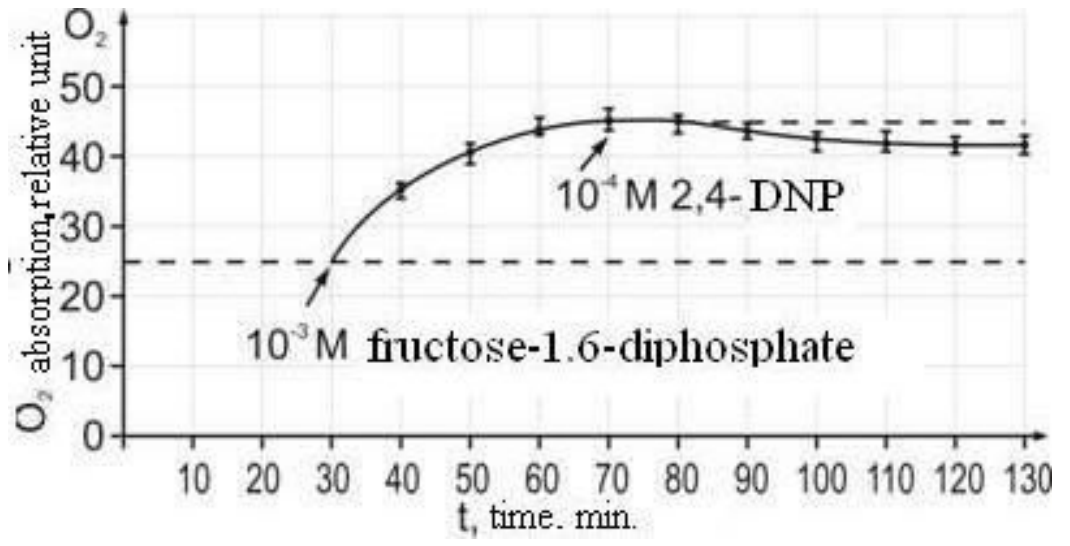

Figure 6 . The kinetics of oxygen uptake by wheat seedlings during prolonged exposure to $\mathrm{NaCl}$ at concentration $70 \mathrm{mM}\left(\mathrm{t}=20^{\circ} \mathrm{C}\right)$.

\section{References}

Baquan S., Maira Th., \& Dulosb E. (2005). Clycolytik oscillations and waves in an open spatial reactor: Impact of feedback regulation of phosphofructokinase. Biophys., chem., 116, 67-76.

Dennis D. \& Coulate T. (1987). The regulatory properties of a plant phosphofructokinase during leaf. Development. Biochem.et Biophys. Acta, 146, 129-137. 
Flores C., Martinez-Costa O., \& Sanchez V. (2005). The dimarfic yeasi Yarrowia lipolytica prosseses an atypical phosphofructokinase characterization of the enzyme and its encoding gene. Microbiol., 151, 1465-1474. http://dx.doi.org/10.1099/mic.0.27856-0

Kasumov N. A. (1983). Physiological \& biophysical aspects of research on the mechanism of salt effects onto vegetative organisms. Baku, "Elm", 141p-s.

Kasumov N. A. (2004). Coordination of breath and glycolysis in plant cells at extreme salinization. Bulletin of the Baku University. Baku, 67-73

Lakin G. F. (1990). Biometry. Moscow. Higher school, 293p-s.

Lee H., \& Copeland L. (1996). Phosphofructokinaze from host fraction of chickpea nodules. Physiol. plant. 96, 607-614. http://dx.doi.org/10.1111/j.1399-3054.1996.tb00233.x

Macdonald J. \& Storey K. (2005). Temperature and phosphate effects on allosteric phenomena of phosphofructokinaze from a hibernating ground squirrel (spermophilus laterialis). FEBSJ. $272,120-128$.

Omarov Y. A. (2007). Phosphofructokinases and their roles in of apple maturation. Author's abstract of dissertation on PhD on Biology. Baku, 20p-s.

Severin E. S. (2004). A textbook on Biochemistry under E.S.Severin's editorship. 2-nd Publishing House-2. Moscow. ГЭОТАР-MED, 784p-s.

Saavedra E., Enqalada R., \& Pineda E. et al. (2005). Glycolysis in Entamoeba histolytica: Biochemical characterization of recombinant glycolytic enzymes and flux control analysis. FEBSJ., 272, 1767-1783. http://dx.doi.org/10.1111/j.1742-4658.2005.04610.x

Santamaria B., Estevez A., \& Martinez-Costa O. et.al. (2002). Creation of an Allosteric phosphofructokinase starting with an Non-allosteric Enzyme. J. Biol. Chem., 277(2), 1210-1216. http://dx.doi.org/10.1074/jbc.M109480200

Sola-Penna M., dos Santos A., \& Alves G. et al. (2002). A radio-assay for phosphofructokinase - 1 activity in cell extracts and purified enzyme. J. biochem. Biophys.Methods, 50, 129-140. http://dx.doi.org/10.1016/S0165-022X(01)00180-4

Susuki M., Hashioka A., Mimura T. \& Ashihara H. (2005). Salt stress and glycolytic regulation in suspension-cultured cells of the mangrove tree. Bruguiera sexandula. Physiol. Plant., 2005, 123, 246-253. http://dx.doi.org/10.1111/j.1399-3054.2005.00456.x

Susuki Mihoco, Hashioka Aya, Mimura Tetsurou, \& Ashihara Hirosmi. (2003). Effect of salt on the glycolytic enzyme activities in salt-resistant mangrove cells, Bruguiera sexandula. Plant and cell physiol. 44, p.30-33.

Torres J., Cuixe V., \& Babul J. A. (1997). Mutant phosphofructokinase produces a futile cycle during glyconeogenesis in Escherichia coli. Biochem. J., 327, 675-684.

Valleyo J., \& Hardin C. (2005). Expression of caveoline in lymphocytes induces caveolae formation and recruitment of phosphofructokinase to the plasma membrane. FASEB Journal, 
19, 586-587.

Van Praag E., Zehavi U., \& Goren R. (1999). Kinetic properties of ATP-dependent phosphofructokinase from grapefruit juice sacs: effect of TCA cycle intermediates. Biocem. Mol. Biol. Int. 47(5), 749-756.

\section{Copyright Disclaimer}

Copyright reserved by the author(s).

This article is an open-access article distributed under the terms and conditions of the Creative Commons Attribution license (http://creativecommons.org/licenses/by/3.0/). 